\title{
OS DESENHOS DA CIDADE OBSERVADA: UMA REFLEXÃO SINGULAR
}

\author{
Alexandre Suarez ${ }^{1}$, Sidney Tamai ${ }^{2}$
}

\begin{abstract}
How are teachers Cartoons observation Architecture Schools in several decades, the idea was to try and explain firsthand the look and fundamental elements of drawings to the Architect. We start looking through the design of: 1 A projective gaze: the invisible is made visible by interactivity and space and time are perceived by the distance that look place between them ; 2nd In bidirectional contamination: the object fills the subject, double- hand, bringing the tactile qualities of architecture in continuous resonance, 3rd Strangeness by slow look : draw as perceptual expansion strategy; 4 Articulation of the structural elements of the design while similar language to architecture and city through the selection of appropriate signs and codes, exclusive and singular.
\end{abstract}

Index Terms: design, city, architecture, art

\section{INTRODUÇÃO}

O Objetivo do artigo é apresentar e refletir sobre nossos Desenhos de observação direta da cidade de Campinas, ao fazer um recorte de cerca de 8 desenhos de lugares típicos ou tópicos com desenhos singulares em suas dinâmicas de linguagem. Como somos professores de Desenhos de observação em Escolas de Arquitetura a várias décadas, a ideia foi experimentar e explicitar in loco o olhar e elementos fundamentais de desenhos para o Arquiteto.

A ação de desenhar a cidade deu-se ao perceber que a cidade tem poucos registros em desenho de sua atividade cotidiana enquanto cidade. Os desenhos de registros da cidade foram iniciados em 2004 e em andamento busca registrar com desenhos de observação livre e técnicas variadas, aspectos da realidade urbana da cidade de Campinas ao revelar as transformações da cidade e seus lugares.

A cidade de Campinas localiza-se no interior do estado de São Paulo, no Brasil e conta com população de 1.080.113, formada a partir de migração e imigração procedentes das mais diversas regiões dos estados, do Brasil e do mundo; a economia está concentrada no setor de serviços ${ }^{1}$ (inserir nota de rodapé aqui "Fonte: IBGE 2010"). A cidade teve vários expoentes nacionais ao longo de sua história, um que se destaca pelo carinho que a população lhe devota ao compositor e maestro Antônio Carlos Gomes, ao arquiteto Ramos de Azevedo e ao inventor isolado da fotografia Hercule Florence que tiveram relevância cultural local e mundial em fins do séc. XIX.
Os desenhos retrataram principalmente a região central da cidade e partes do Bairro Cambuí. Alguns locais que foram registrados foram: Mercados Municipais, Terminal central de ônibus, Rodoviária, Centro de Ciência Letras e Artes, Centro de Convivência Cultural, Estação Ferroviária, Diversas Ruas como a Francisco Glicério, Barão de Jaguara, 13 de Maio, além de outros semelhantes.

Os procedimentos para a realização dos desenhos foram básicos, como o caderno de papel canson com formatação quadrada de $20 \mathrm{~cm}$. por $20 \mathrm{~cm}$.; lápis de diversos tipos $(2 \mathrm{~B}, 4 \mathrm{~B}, 6 \mathrm{~B}$, integral, lapiseiras etc.) canetinhas e lápis coloridos. Um banquinho de pescador para sentar durante a realização dos desenhos. O tempo de cada investigação: em geral era dedicada uma manhã de um dia para a realização dos desenhos, em média os desenhos foram realizados em 30 minutos, o quê ao longo de uma manhã, resultava em cerca de 4 a 8 folhas de desenhos. Para a realização dos registros havia um encontro matinal em um café na região central da cidade, onde se discutia qual a região ou local da cidade seria investigado (edifícios institucionais, parte interna ou externa dos edifícios, ruas etc.) discutia-se qual seria a temática do dia (desenhar pessoas, ou detalhes, ou edifícios), por fim, também se discutia qual seria a técnica adotada (desenho de vazios, ou com cores etc.). Essas definições eram norteadoras nas atividades que seriam desenvolvidas na manhã, mas cada autor tinha liberdade para alterar qualquer parâmetro anteriormente definido.

Os autores realizaram, com assiduidade, encontros semanais, para a realização desse trabalho durante os anos de 2004 a 2008 e atualmente os encontros são esporádicos.

\section{AbORdagem}

\footnotetext{
${ }^{1}$ Alexandre Suarez de Oliveira - Prof. Dr. Unesp FAAC - Universidade Estadual Paulista “Julio de Mesquita Filho" - alexarq@ faac.unesp.br

${ }^{2}$ Sidney Tamai - Prof. Dr. Unesp FAAC - Universidade Estadual Paulista “Julio de Mesquita Filho” - sidneytamai@faac.unesp.br
} 
Em um diálogo entre conceitos e experimentações, o artigo expõe a produção de desenhos a quatro questões teóricas que podem qualifica-los na produção de uma ampliação no entendimento da cidade através de desenhos. $1^{\circ}$ Como um olhar projetivo: onde o invisível é tornado visível por interatividades e o espaço e tempo são percebidos pela distância que o olhar coloca entre eles; $2^{\circ}$ A contaminação bidirecional: o objeto inunda o sujeito, em dupla mão, trazendo as qualidades táteis da arquitetura em contínua ressonância; $3^{\circ} \mathrm{O}$ estranhamento por lentidão do olhar: desenhar como estratégia de dilatação perceptiva; $4^{\circ} \mathrm{A}$ articulação dos elementos estruturantes do desenho enquanto linguagem análoga à arquitetura e cidade através da seleção de sinais e códigos apropriados, exclusivos e singulares $3^{3}$.

Segue pequena parte da produção de desenhos da cidade de Campinas e as questões conceituais ampliadas que atravessam essa leitura gráfica da cidade. Outros podem ser vistos no site da revista Vitruvius, nesses links de Sidney Tamai e Alexandre Suarez: http://www.vitruvius.com.br/jornal/charges/490?page=02\&c artoonauthor $=21 \&$ lang $=\mathrm{pt}$,

http://www.vitruvius.com.br/jornal/charges/520?page=01\&c artoonauthor $=30 \& l a n g=p t$

\section{Série de desenhos de Sidney Tamai: \\ DESENHOS}
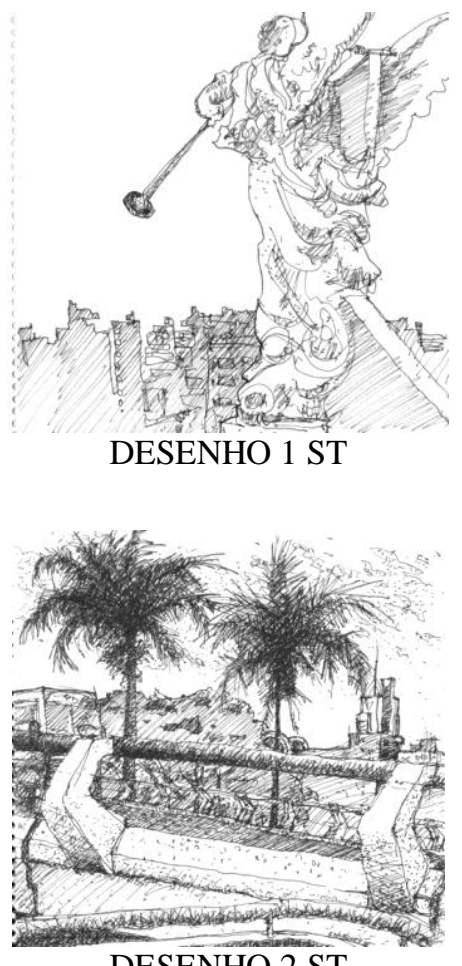

DESENHO 2 ST

\footnotetext{
${ }^{3}$ Nesse item, as questões partem de proposições de Massironi e Arnheim, que constam na bibliografia e pelos autores em artigo para o Seminário Internacional Graphica 2013.
}
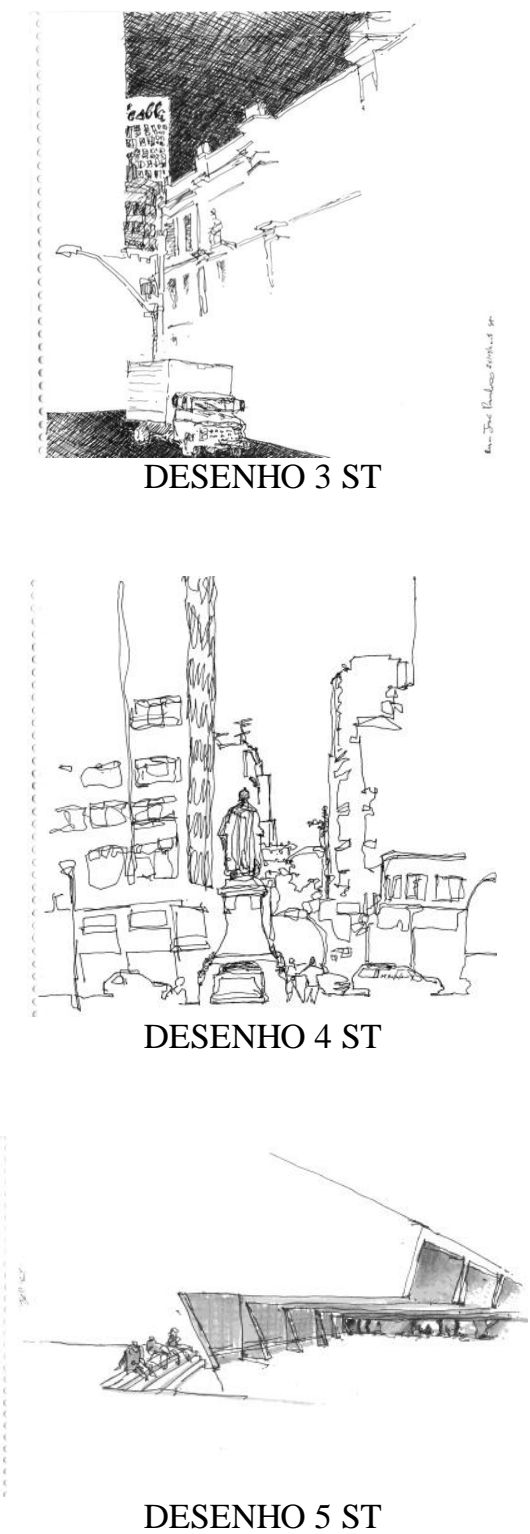

Série de desenhos de Alexandre Suarez:

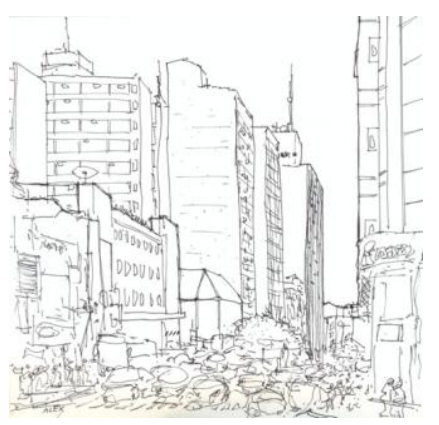

DESENHO 1 AS 


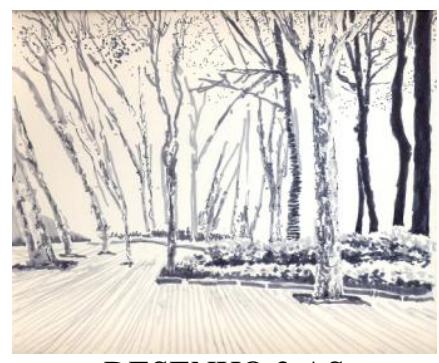

DESENHO 2 AS
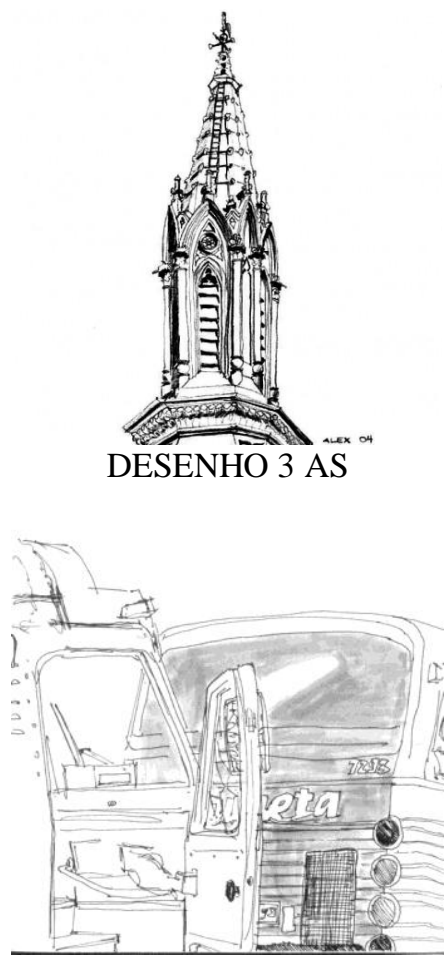

DESENHO 4 AS

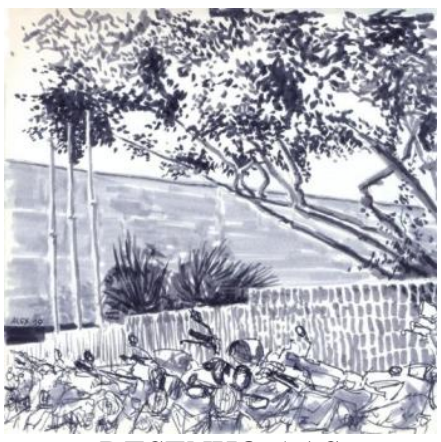

DESENHO 5 AS

\section{DESENVOLVIMENTO DA PROPOSTA}

Para um maior entendimento dos desenhos serão desenvolvidos esses princípios norteadores para melhor resolver e operar a relação entre o olhar e o desenhar a arquitetura e a cidade.
A primeira questão é a do olhar projetivo onde o invisível é tornado visível por interatividades e o espaço e tempo é percebido pela distância que o olhar coloca entre eles. Ver é prever. Nesse entendimento do projetivo alguns elementos são estruturantes, como a articulação de sinais e códigos, e a relação de enfatismo e exclusão na construção de linguagens gráficas, é o que leremos adiante.

Operar por Enfatismo é grafar acentuadamente alguns aspectos-códigos, até sua eliminação. Operar por Exclusão é adicionar qualidade ao signo por subtração de elementos gráficos. Há aqui portanto uma relação entre essa abordagem e entre os conceitos de Ocultamento e Apagamento no desenho da cidade, ocultamento enquanto potência do virtual e apagamento como adição por subtração. (DESENHO 3 ST e DESENHO 2 AS)

Ver funciona como prever (virtual projétil), onde o invisível (não visto) é construído também como linguagem via repertório do interpretante. Ao que não está presente fisicamente é preciso uma ponte, construí-lo via linguagem. Nesse processo de linguagem o leitor seleciona, filtra e completa uma imagem invisível como se visível fosse. Interatividade.

Um olhar é lançado de algum lugar para outro lugar. Quando se olha, seu olhar desloca-se até a coisa observada percorrendo-se uma distância. Coloca uma distância entre o sujeito-interpretante e os objetos, logo entre os próprios objetos criando espaços e tempos não homogêneos dada a diversidade de qualidade signica entre eles.

Essa atitude de olhar pressupõe e propõe alguém, singular, único, que olhe através do desempenho dos olhos. Alguém que olha, e que está contaminado com outros sentidos que leem espacialidades e temporalidades múltiplas. Este é um plano de puras qualidades, e é essa teia de sensibilidades dos sentidos que se vedam e se revelam e que se rompem em um olhar. É a base do pensamento visual.

A segunda questão, a da contaminação bidirecional onde o objeto inunda o sujeito, em dupla mão, trazendo as qualidades táteis da arquitetura e em contínua ressonância, transforma-o em seu objeto.

O olhar é bidirecional porque possui uma dinâmica de trocas informativas, onde as informações migram entre as formas-estruturas por tendência ao equilíbrio. Se há um sujeito que olha e um objeto olhado, esse processo não é exclusivamente unidirecional. Pelo mesmo canal que se olha, se é olhado pelo objeto, pois não há um controle de entrada. $\mathrm{O}$ objeto inunda o sujeito, e em certo sentido de dupla mão transforma-o em seu objeto (o objeto do objeto que se torna sujeito, que novamente se torna objeto e assim indefinidamente).

Dessa tendência de equalizar as informações de um sistema, surge um sujeito. Um novo sujeito-interpretante, que como alguém de fora (um outro, não imerso) recoloca uma nova ordem nas relações sujeito/objeto através de novos signos. 
Há, portanto, uma profunda contaminação bidirecional, sujeito (interpretante)-objeto pelo olhar. Se vemos um filme, sua realidade nos invade e nos modifica. Se vemos na praia um mar noturno, seu cheiro, seu som, a areia. Através das nossas experiências essa forma de mar migra, envolve e invade-nos tornando-nos objeto desse mar de qualidades. Um novo sujeito-interpretante forma-se nas suas novas nomeações de signos para o mar. Um espaço de qualidades arquitetônicas age da mesma forma, em nós. (DESENHO 2 ST, DESENHO 5 AS)

Nas palavras de Rudolf Arnheim: “...a feitura da imagem artística ou não, não provém simplesmente da projeção ótica do objeto representado, mas é um equivalente, interpretado com as propriedades de um meio particular, do que se observa no objeto".(Arnheim, 1980: 90)

A terceira questão, do estranhamento por lentidão do olhar-desenhar e como estratégia de prolongamento perceptivo.

Enquanto professores de desenho, nos trabalhos desenvolvidos com os alunos sempre são apresentados ou discutidos a necessidade de gerar estranhamento. Estranhamento como nos coloca Chklovsky em sua "Arte como procedimento". Estranhar para dificultar o acesso e prolongar a percepção. Isso aumenta o grau da experiência e de conhecimento sobre o objeto.

Desenhos nomeados de cegos (sem olhar para o papel), desenhos semi-cegos (olha-se pouco para o papel e estrutura-se a forma) e desenhos de vazios (onde o negativo é espaço organizador) são parte de entendimento de um desenho mais tátil. $\mathrm{O}$ desenho cego valoriza um olhar tátil e oposto ao olhar perspectivado, unificador e auto centrado renascentista. Um olhar de detalhes, de entre coisas, topológico, líquido que navega de uma coisa a outra como continuidade. Cria um repertório de linhas, ondulações, texturas, espessuras e uma memória tátil por onde se olha e se desenha. Amplia o universo sensível e o espaço por onde percorre os olhos se apresenta como um lugar.

Os desenhos de Vazios é o desenho do informe, se referem aos desenhos do entre coisas e que podem ser: 1 . vazios diretos ou das próprias coisas constituídas também de matéria e vazios. Ex: a forma dos espaços entre as pernas do banco e o vidro da janela em qualquer posição. 2. vazios indiretos, são os vazios menos significativos entre uma coisa e outra. Ex: A mancha formada pelo branco do olho naquela posição. Os vazios estabelecem uma continuidade entre tudo que é espaço e através da exercitação direta educa o olhar para ver e perceber os espaços e ainda mais a olhar atentamente através dos vazios que é visto como o espaço negativo, mas que para as artes e para a arquitetura é positivo e propõe ao aluno olhar para o que não é para ver o que é.

Prolongar o tempo do olhar é modificar a forma de olhar e também a tendência imediata de classificar de juntar pontos, espaços, formas e nomear. Não visa o encontro de uma Gestalt, ao contrário é não dirigir o que se vê a uma forma pré-existente no seu repertório ou imaginário formal. É ir vendo todas as nuanças, variações, oscilações, densidades, distâncias do que se constrói a forma ou o seu vazio. Constituem-se de desenhos que exploram a lentidão do olhar. Lentifica-se o olhar através de um zoom que detalhe os pormenores. Perde-se a noção do todo e se vai à estrutura do fluxo das linhas e sua complexidade de movimentos e tensões navegando nas linhas fluidificadas. Ampliam-se o repertório sensível de imagens, detalhes, movimentos. (DESENHO 3 ST, DESENHO 4 AS)

É com essas nuanças de detalhes, proporções e oscilações que se afirma algo como desenho. Ao nominar, se estabelece uma simetria entre nome e forma criando uma barreira para se desenhar algo que não seja o pré-desenhado, redundante e de limitadas variáveis estocadas no imaginário como uma biblioteca de imagens. Biblioteca quantitativa, fechada, que o dono pouco modifica e difícil gerar conhecimento e afirmações espaciais, funcionando como algo que repõem as coisas no mundo em uma certa ordem espacial e menos como propositores espaciais de um mundo.

Com esse olhar qualidades táteis aparecem para revelar o espaço-tempo arquitetônico através de desenhos cego, semi-cegos com lentidão para se presenciar fluxo das linhas, vazios e pontos e perceber os vazios como continuidades espaciais.

Finalizando, a quarta questão, a articulação dos elementos estruturantes do desenho enquanto linguagem espaço-temporal análoga à arquitetura e cidade através da seleção de sinais e códigos apropriados e exclusivos para desenhos singulares.

No conjunto de desenhos, tanto de Alexandre Suarez como os de Sidney Tamai, procurou-se as qualidades táteis para revelar o espaço-tempo arquitetônico e perceber os vazios como continuidades espaciais. Mas sempre se considerou o que o lugar pede, lugar nem sempre convencional da cidade. A condição específica do lugar foi sempre considerada. Os níveis sintáticos (escalas, cores, luzes, texturas), semântico (uso, função, proposição) e pragmático (como de fato é usado, visto e entendido pela população) identificam a abordagem gráfica do desenho.

(DESENHOS 1 e 4 ST, DESENHOS 1 e 5 AS)

Não será necessário apontar especificamente para cada desenho, pois são visíveis desenhos que apenas utilizam linhas pra relações sky line da cidade, densidades gráficas de sombras para espaços duros e pouco visitados. Jogo entre sombras densas e linhas fluídas para apontar os contrastes e conflitos da cidade. Há portanto infinitas opções que os tornam únicos enquanto desenhos da cidade.

\section{CONCLUSÃO}

Essas possibilidades de desenhar nos leva as questões estruturadas pelo artigo, a do olhar projetivo e interativo que dependendo como se desenha coloca distância e completudes assimetricas entre os elementos da cidade 
revelando distâncias não previstas e convencionais na dinâmica da cidade.

Outro ponto foi a contaminação bidirecional entre quem observa, desenha e quem é observado, desenhado. Aqui como o desenho ganha características táteis em função de texturas específicas e índices propositalmente apresentados, desloca o olhar perspectivado para uma experiência mais cinestésica corporal da imagem da cidade.

A lentidão do olhar que gera estranhamento faz ampliar os níveis de detalhes de forma seletiva, apenas o que interessa para aquele situs. Ao perder a ideia de unidade, ao não nomear de ante-mão o espaço e sua imagem de forma simbólica, acabam por atuar em continuidade sujeito-cidade. O desenho passa a ser extensão sensível da cidade, um signo com qualidades indiciais da cidade.

Finalizando, a seleção de sinais e códigos do desenho em continuidade com a cidade é entendida como continuidade em tradução de um olhar para o meio gráfico, portanto são elementos gráficos e ficticios como são ficcionais a estrutura dos desenhos para ler, interpretar a cidade. A cidade tridimensional, viva, histórica, dinâmica é apresentada por essa forma de interpretar e traduzir. Portanto os desenhos são sempre específicos para cada situação espacial específica.

Alguns desenhos contemplam mais alguns aspectos abordados enquanto outros, pelas suas características e o que problematizam graficamente, articulam outros elementos que geram novas signagens.

Concluindo, o interessante nesses registros, objetivos nas suas subjetividades é que desenhar, além de educar o olhar, faz você conhecer melhor a cidade. Utilizamos recursos amplos de técnicas de desenhos, mas somente usamos o necessário para cada situação, para inventar linguagens gráficas. $\mathrm{O}$ conjunto de desenhos obtidos, acreditamos, revela a diversidade das qualidades dos lugares da cidade de Campinas.

Como arquitetos, desenhistas e professores de desenho procuramos articular os meios de desenhar, os caminhos para interagir com a cidade de forma intensa e reveladora da sua diversidade na direção da civilidade.

\section{REFERÊNCIAS BIBLIOGRÁFICAS}

ARNHEIM, Rudolf, Arte e percepção visual, Ed. Edusp - 1980 - SP - 503 pgs

ARTIGAS, Vilanova. Texto da Aula Inaugural pronunciada na Faculdade de Arquitetura e Urbanismo da USP em 1 de março de 1967. Reedição da publicação do Centro de Estudos Brasileiros do Grêmio da FAU-USP, 1975 CHKLOVSKI, Victor. A arte como procedimento, In: Teoria da Literatura - formalistas russos ; Dionísio de O. Toledo(org.). Porto Alegre, editora Globo, 1976, pp. 39-56.

DERRIDA, Jacques. Entrevista de Hélêne Viale, in: Diagonal no 73 , agosto de 1988, pp. 37-39.

Las artes espaciales. Entrevista com Jacques Derrida realizada por Peter Brunette e David Wills.

In:http://www.accpar.org/numero1/derrida1.htm. Capturada em 8 de agosto de 2008.

EDWARDS, Betty. Desenhado com o lado direito do cérebro. 2. ed. Rio de Janeiro, Ediouro, 2000.
MASSIRONI, M.“Ver pelo desenho,"Ed. Martins Fontes, 1982. SP PINKER, Steven. Como a mente funciona. São Paulo, Cia das Letras, 1999.

TAMAI, Sidney In: "Potencia signica na passagem dissimetrica entre artes" st - : "Potencia signica na passagem dissimetrica entre artes" Arte e Tecnologia - 2011 - UNB

VALLE, Marco Antonio Alves; Processo de apagamento em escultura: limites entre o Moderno e o Contemporâneo. Oculum (PUCCAMP). , v.2, p.60 - 70, 1992., Oculum Ensaios (PUCCAMP), Vol. 2, pp.60-70, Campinas, SP, BRASIL

ZEVI, Bruno -"Saber ver a Arquitetura" (1), Edições Martins Fontes SP Brasil 220 pgs 1978 